\title{
Introdução à Eletrodinâmica Atmosférica
}

\author{
Introduction to the Atmospheric Electrodynamics
}

\author{
Odim Mendes Jr.* \\ DGE-CEA/INPE, Caixa Postal 515, 12201-970, \\ São José dos Campos, SP \\ Margarete Oliveira Domingues ${ }^{\dagger}$ \\ LMO-CPTEC/INPE, Cx. P. 515, 12201-970 \\ São José dos Campos, SP
}

Recebido em 6 de agosto, 2001. Aceito em 21 de janeiro, 2002.

\begin{abstract}
A Eletrodinâmica atmosférica governa os processos físicos na Terra, afetando a vida, instalações e serviços tecnológicos. Com o objetivo de auxiliar os professores, pesquisadores e estudantes a lidarem com esta área e suas conseqüências, o ambiente eletrodinâmico é apresentado neste tutorial.

The Atmospheric Electrodynamics rules important processes in the Earth, affecting the life, installations and technological services. In order to help teachers, researches and students to deal with this area and their consequences, the electrodynamical environment is presented in this tutorial.
\end{abstract}

\section{Introdução}

Este texto tem o propósito de apresentar aos professores, estudantes e pesquisadores uma visão abrangente e algo aprofundada de uma área que está se tornando cada vez mais importante: a Eletrodinâmica Planetária. Devido às inovações tecnológicas e serviços disponíveis para a sociedade humana, como por exemplo, recursos de telecomunicações, recursos sofisticados de informática e vôos de aeronaves de passageiros sob novos projetos técnicos, esse assunto constitui-se um nicho de mercado a ser explorado e de inadiáveis pesquisas para entendimento de variados fenômenos. Servindo de base também para o entendimento de fenômenos do Espaço Próximo (região onde transitam astronautas e sondas espaciais) e de fenômenos da Aeronomia (região de atmosfera ainda relativamente densa mas de alta ionização), este trabalho preocupar-se-á com processos físicos de eletrificação geral da atmosfera e das descargas elétricas na baixa atmosfera $(\leq 70 \mathrm{~km})$ pela sua importância ampla e imediata.

Em geral, os processos naturais mostram-se de comportamento complexo, de medição complicada, exigindo investigações multidisciplinares. A Eletrodinâmica Atmosférica, que é parte da Eletrodinâmica Planetária, enquadra-se plenamente nessa categoria de fenômenos, requerendo planejamentos inter-institucionais, perseverança de análise nos tópicos investigados e discussões intensivas de profissionais de diferentes áreas do conhecimento. Atualmente, concernentes aos estudos mundiais de Ciências Espaciais, Atmosféricas e Oceânicas, vários aspectos têm sido considerados para a modernizacão dessas áreas. O monitoramento da atividade elétrica, em bases contínuas ou em campanhas completas, coordenadas e intensivas, está entre as ferramentas consideradas nessa modernização.

Nela, entre as diretrizes principais estão saber estabelecer questões-chave, coletar informações adequadas e dispor de pessoal adequado. O conhecimento resultante contribuirá para aplicações diretas na modelagem numérica do tempo e do clima para fins que afetam diretamente a sociedade civil, inclusive nas áreas de saúde; lazer e turismo; os setores produtivos, seja na agricultura e pecuária, seja em diversos setores da atividade industrial; além da segurança dos transportes aéreos, terrestres e marítimos; da geracão e distribuição de energia e gerenciamento da água, dentre outros. Atualmente discute-se a extensão dos conceitos de tempo e clima para regiões que não estão restritas à atmosfera próxima ao solo.

Dadas às características continentais do território nacional (extensão e posicão geográfica), há a necessidade de estabelecer tanto abordagens espaciais amplas como abordagens peculiares a regiões específicas, o que requer o conhecimento dos múltiplos aspectos de

\footnotetext{
*odim@dge.inpe.br, http://www.dge.inpe.br/wotan
}

$\dagger^{\dagger}$ margaret@cptec.inpe.br 
quaisquer fenômenos sob investigação. Por exemplo, observa-se na meteorologia brasileira que muitos dos modelos conceituais de previsão de tempo atualmente em vigor possuem sua concepção original associada a observações e análises físicas dos fenômenos ocorridos em regiões temperadas da Europa, América do Norte e Ásia. De uma forma geral, eles podem ser utilizados em certas situações no Brasil; entretanto, esses modelos não se aplicam irrestritamente a muitos dos fenômenos que diariamente são observados nos trópicos. Conhecer melhor os processos físicos geradores dos sistemas de tempo, suas iterações entre escalas (larga escala, escala sinóptica, meso escala, escala local e microescala) e seu padrão de comportamento (temporal e espacial) nas diversas regiões do Brasil é de vital importância na melhoria da previsão regional.

Atualmente, entre as análises da atmosfera associadas às condições de tempo de interesse da sociedade, deve-se considerar o monitoramento da atividade elétrica atmosférica em suas várias formas de estudo (modelagem matemática, investigações físicas, experimentações de engenharia, etc.) e de suas potenciais aplicações, que, na parte de coleta experimental de informações de superfície, pode contar com (a) sistemas de detecção e rastreio de relâmpagos; (b) sistemas de imageamento de fenômenos atmosféricos (nuvens, relâmpagos, sprites, e outros fenômenos ópticos transientes); (c) sistemas de monitoramento acústico da atividade elétrica, em especial do trovão; (d) sistemas de monitoramento do campo elétrico atmosférico (AC/DC) - detectores field mill, detectores de sferics e detectores similares; e (e) sistemas de integração das informações elétricas às demais informações atmosféricas. A essas acrescentam-se ainda outras tecnologias recémaprimoradas de monitoramento com o uso de satélites e de vários tipos de radares.

Para levar a termo esse tipo de acão, é necessário o desenvolvimento e/ou a adoção de equipamentos tecnológicos avançados. No entanto, primordialmente, há a necessidade de formação ou capacitação de recursos humanos para a investigação proficiente da física dos fenômenos, do tempo e do clima, e também da apropriação tecnológica pertinente.

Assim, o propósito deste tutorial é colaborar para a modernização dessas áreas de estudo no Brasil por meio do fornecimento de uma visão geral do assunto Eletrodinâmica Atmosférica e pelo incentivo ao desenvolvimento de núcleos multidisciplinares ou surgimento de novos núcleos de estudo. Esse texto, portanto, apresenta de forma sucinta: o ambiente eletrodinâmico que envolve a Terra; o cenário abrangente da Eletricidade Atmosférica; elementos do Circuito Elétrico Atmosférico Global ( $C E A G$ ); e tópicos de pesquisa em Eletrodinâmica Planetária.

\section{O ambiente eletrodinâmico da terra}

O Sol é o agente primário dos processos naturais na Terra e também sustenta a vida na litosfera. Inicialmente apresenta-se o conhecimento básico sobre a gênese do ambiente eletrodinâmico terrestre $[1,2]$, que envolve a física do Sol, o campo magnético interplanetário e o acoplamento Sol-Terra.

\section{II.1 A física solar}

O Sol é uma estrela como muitas outras que existem no Cosmo. Apresenta distância do centro da ViaLáctea de $3 \times 10^{16} \mathrm{~km}$, velocidade angular em torno do centro galáctico de $200 \mathrm{~km} / \mathrm{s}$, raio solar médio de $6,96 \times 10^{5} \mathrm{~km}$, e massa de $2,0 \times 10^{30} \mathrm{~kg}$. A atmosfera gasosa do Sol gira mais rápido no equador do que nos pólos, apresentando um período médio de 27 dias terrestres. Em 22 anos completa-se um ciclo de inversão da polaridade do campo magnético do Sol. As reações nucleares acontecem no centro do Sol, onde a temperatura é de $10^{7} \mathbf{K}$ e a pressão é de $10^{11}$ atm terrestres. A seguir, a energia escapa na forma de radiação (na região de 0,2 a 0,8 raio solar). Daí até a superfície visível, a energia é transportada por convecção de matéria. O Sol e os planetas foram provavelmente condensados da matéria gasosa interestelar em torno de 5 bilhões de anos atrás. O Sol é cerca de $70 \%$ em massa composto de hidrogênio com pequenas quantidades de quase todos os elementos. Podem-se considerar dois modelos básicos para o Sol.

No Modelo do Sol Calmo, o Sol é visto como uma bola de gases quentes, simetricamente esférica e estática. Isso significa que as propriedades solares mudam apenas com a distância radial e que se apresentam uniformes sobre qualquer casca esférica. Neste modelo estratifica-se o Sol em camadas características, que são:

Núcleo: região em que, sob a própria atração gravitacional, a matéria solar é comprimida a uma elevada densidade e elevada temperatura, de forma que as reações nucleares ocorrem. Essas reações são a fonte de energia que está continuamente irradiando para o espaço e produz a atividade solar. Tem a espessura de 0, 2 raio solar.

Zona intermediária: região em que a energia inicialmente escapa na forma de radiação e a seguir fazse em processo de difusão. Tem a espessura estimada de 0,6 raio solar.

Zona de convecção: região em que o processo turbulento de convecção de matéria domina no transporte de energia. Tem a espessura de 0,2 raio solar.

Fotosfera: região do Sol em que a maior parte da energia é emitida na forma de radiação visível. Tem a espessura de $300 \mathrm{~km}$. 
Cromosfera: região acima da fotosfera com tom avermelhado (devido ao efeito de absorção e reemissão da radiação eletromagnética $\mathrm{H} \alpha$ ). Tem a espessura de $15000 \mathrm{~km}$.

Coroa solar: região mais externa do Sol que se estende para o meio interplanetário. Ela é a fonte do vento solar. Tem a espessura superior a $2 \times 10^{6} \mathrm{~km}$.

A Fig. 1 apresenta a estratificação solar e o fluxo de energia do interior para o exterior.

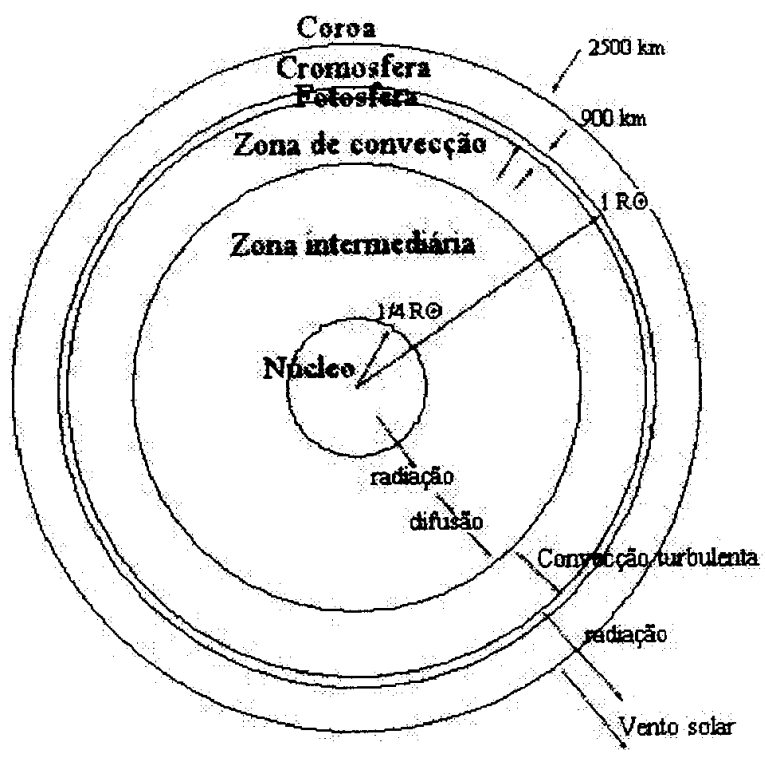

Figura 1. Estratificação solar e fluxo de energia.

A região coronal do Sol apresenta-se tão quente $\left(10^{6} \mathrm{~K}\right)$ que mesmo a sua enorme força gravitacional não consegue reter as partículas que a populam. Dessa forma, parte da coroa está constantemente "evaporando", isto é, escapando em um fluxo aproximadamente constante para longe do Sol, e forma o que é denominado vento solar. O vento solar caracteriza-se por ser um plasma (gás ionizado de comportamento coletivo e macroscopicamente neutro), essencialmente formado de prótons, elétrons e hélio; cuja velocidade varia de aproximadamente 200 a $1000 \mathrm{~km} / \mathrm{s}$ que tem uma densidade aproximada de 10 partículas $/ \mathrm{cm}^{3}$.

Em contraste, o Modelo do Sol Ativo considera os processos que ocorrem em regiões localizadas da atmosfera solar e dentro de intervalos finitos de tempo. As causas da atividade solar são o campo magnético de grande escala do Sol e a sua rotação diferencial (do Sol). O campo magnético solar não provém de um dipolo no interior do Sol (como o da Terra); porém parece resultar da contribuição dos vários campos produzidos nas camadas superficiais do Sol. A interação complexa do campo magnético solar com a sua rotação diferencial produz perturbações localizadas no Sol, permitindo a liberação de energia magnética na forma de energia cinética. Isso produz, entre outros fenômenos, explosões solares e proeminências eruptivas e, às vezes, por consequência, ejeções de matéria coronal. Isso sobrepõe-se à radiação eletromagnética normalmente emitida pelo Sol. As explosões são essencialmente uma liberação abrupta de energia provavelmente extraída do campo magnético das manchas solares, capaz de acelerar elétrons e íons até altas energias. Já a proeminência eruptiva é um arco de plasma solar aprisionado nas linhas magnéticas que se expande para longe do Sol.

\section{II.2 O campo magnético interplanetário}

O campo magnético do Sol, por estar imerso em um plasma, destaca-se do Sol penetrando no meio interplanetário. Por efeito de propriedades magnéticas, esse campo propaga-se congelado no vento solar. Devido à rotação do Sol, isso dá origem a uma configuração espiral (Espiral de Arquimedes, Fig. 2). Assim, as linhas de campo magnético solar em um hemisfério afastamse e no outro aproximam-se, até sofrerem ao longo do tempo uma inversão, o que caracteriza entre outros efeitos o Ciclo de atividade solar. Em consequência de uma lei física de continuidade, surge entre os campos magnéticos interplanetários de orientações opostas uma lâmina de corrente elétrica, que se apresenta ondulada (com 2, 4 ou 6 setores).

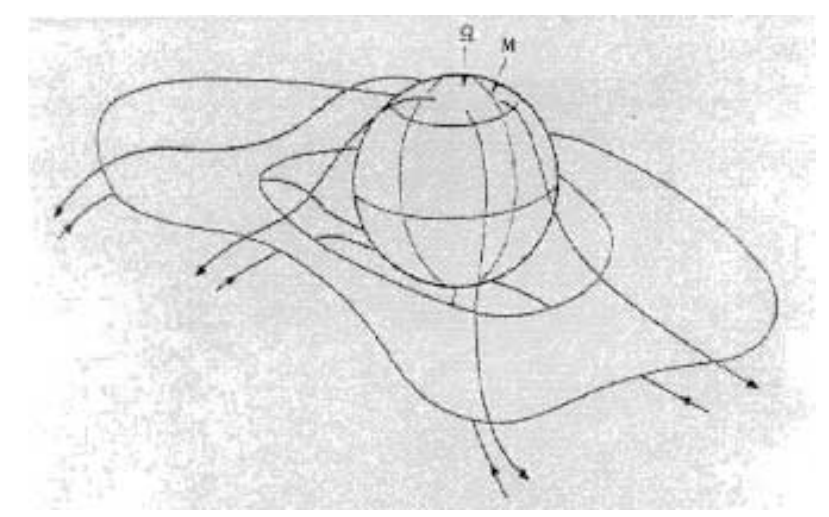

Figura 2. Configuração espiral do campo magnético e lâmina de corrente elétrica heliosférica.

A intensidade e a orientação do campo magnético interplanetário e a densidade, a composição e a velocidade do plasma solar dependem de fenômenos que ocorrem no Sol e no meio interplanetário. Esses fenômenos podem ser relacionados sucintamente como:

Setor de lâmina de corrente: região de corrente elétrica existente pela descontinuidade do campo magnético heliosférico.

Choque interplanetário: um feixe de plasma que se desloca supersonicamente no meio interplanetário. Caracteriza-se pelas alterações 
abruptas dos parâmetros interplanetários (densidade, temperatura, velocidade do plasma solar e orientação e intensidade do campo magnético interplanetário).

Interação de feixes interplanetários: um feixe mais rápido que alcança um feixe mais lento. Caracteriza-se geralmente por uma interface nos parâmetros densidade, velocidade e temperatura do plasma solar.

NCDE (Noncompressive Density Enhancement): uma elevação de densidade do plasma solar que não foi produzida por compressão do meio interplanetário, porém gerada no próprio Sol. Caracteriza-se pela elevação na densidade quando a velocidade está decrescendo.

Flutuações do tipo ondas alfvênicas: perturbação do meio interplanetário que se caracteriza por flutuações correlacionadas dos parâmetros velocidade do plasma solar e das componentes do campo magnético interplanetário.

\section{II.3 O acoplamento Sol-Terra}

A radiação eletromagnética do Sol tanto aquece quanto ioniza a atmosfera terrestre. Como a Terra possui um campo magnético, o vento solar incidente interage com essa atmosfera ionizada e magnetizada, estabelecendo uma região espacial dinâmica que envolve a Terra, denominada Magnetosfera, em que os processos físicos são dominados pelo campo geomagnético (Fig.3). Essa região física é de importância nos processos de deposição de energia e de matéria na atmosfera terrestre.

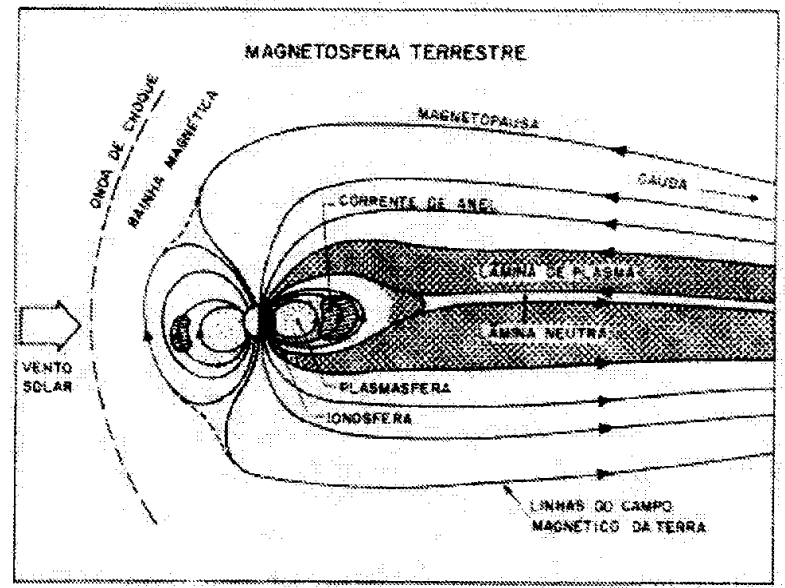

Figura 3. Uma visão simplificada das regiões que compõem e envolvem a magnetosfera terrestre.

Grosso modo, as regiões da magnetosfera podem ser classificadas de diferentes modos, como, por exemplo, quanto a regiões de linhas magnéticas fechadas ou abertas; quanto ao tipo e organização do plasma; etc. Essencialmente, no lado diurno há um achatamento da magnetosfera e no noturno, um prolongamento, constituindo uma cauda magnetosférica. Essa cauda pode armazenar energia com a liberação posterior gradual ou abrupta e também na forma de uma bolha de plasmas (esta denominada plasmóide). O vértice polar permite acesso direto do plasma solar à região da atmosfera superior da porção diurna da região auroral. Nas regiões de mais baixas latitudes, as partículas incidentes também contribuem para o estabelecimento de correntes elétricas, contribuindo para a energização e a população das altas camadas (distância superior a 3 raios terrestres).

O fluxo de energia do vento solar é muito menos intenso que o fluxo de energia da radiação visível; porém a secção eficaz de choque é muitas vezes maior. A energia potencialmente suprida pelo vento solar é de aproximadamente $3,0 \times 10^{6}$ megawatts. A pressão dinâmica do vento solar ou fluxo de momentum controla o tamanho da magnetosfera. A orientação e a intensidade do campo magnético interplanetário controlam a taxa do fluxo de energia dentro da magnetosfera e esse processo de energização não é estacionário. Como os fenômenos de atividade solar e do meio interplanetário afetam o acoplamento eletrodinâmico terrestre e, em decorrência, afetam os dispositivos eletroeletrônicos e o ecossistema, uma nova área de atuação tem se definido atualmente, no sentido de monitoramento de um tempo espacial e mesmo de um clima espacial. Essa nova preocupação científica e tecnológica tem sido designada de Space Weather Forecasting.

Assim, esse cenário eletromagnético e eletrodinâmico cria efeitos os mais diversos - com aquecimentos, campos elétricos e correntes elétricas - na atmosfera terrestre, produzindo a mais variada ordem de fenômenos, com várias escalas espaciais e temporais de ocorrência.

\section{A eletricidade atmosférica}

O tópico Eletricidade Atmosférica faz parte da área de pesquisa Eletrodinâmica Planetária [3,4,1]. Esse é um tópico multidisciplinar, sendo que a abordagem fundamental é o Eletromagnetismo. Apresenta-se a seguir o arcabouço básico desta área de investigação, principalmente para os que não tiveram oportunidade de contato com este assunto, e que bem provavelmente terão de estender pesquisas sobre um ou outro tópico. Fruto das pesquisas recentes dos autores conduzidas no INPE, o propósito desse tutorial é despertar o interesse e motivar a atuação de profissionais de várias áreas (física, meteorologia, matemática, engenharia, etc.) em pesquisas cooperativas e integradas. Esse texto desenvolver-se-á em torno dos campos eletromagnéticos de baixa frequência, em muitas situações, campos que poderão ser considerados estacionários. A 
eletricidade atmosférica de baixa altitude volta a despertar um interesse significativo da comunidade internacional, pelas recentes constatações físicas, que revelam o caráter integrado de toda a atmosfera. Isto é, a troposfera (região até aproximadamente $15 \mathrm{~km}$, em que a temperatura cai com a altura) mostra-se acoplada eletricamente à média e à alta atmosferas, e de uma forma bastante ativa. Muitas das propriedades elétricas da atmosfera podem ser tratadas pela eletrostática. A abordagem eletrostática pode ser considerada quando as interações entre as cargas dependem da sua posição relativa e não dos seus movimentos. Mesmo os relâmpagos, que não são evidentemente estáticos, podem ser inicialmente tratados assim.

\section{III.1 Elementos de eletricidade e mag- netismo}

A natureza tem uma propriedade elétrica intrínseca. Com isso, quer se dizer que há uma propriedade fundamental nas partículas elementares que compõem os objetos materiais, a carga elétrica. Essa propriedade básica pode ser revelada quando se atritam os cabelos com um pente em uma atmosfera mais seca e, então, se aproxima esse pente de pequenos pedaços de papel. Os papéis são inicialmente atraídos e depois repelidos pelo pente. Fenômeno semelhante ocorre ao se friccionar um bastão de vidro com um pedaço de seda ou um bastão de âmbar com um pedaço de pele de gato ou, ainda, quando se atrita o braço em um pedaço de isopor. A propriedade que esses experimentos identificam recebe o nome de eletricidade, derivado da palavra grega elektron que significa âmbar.

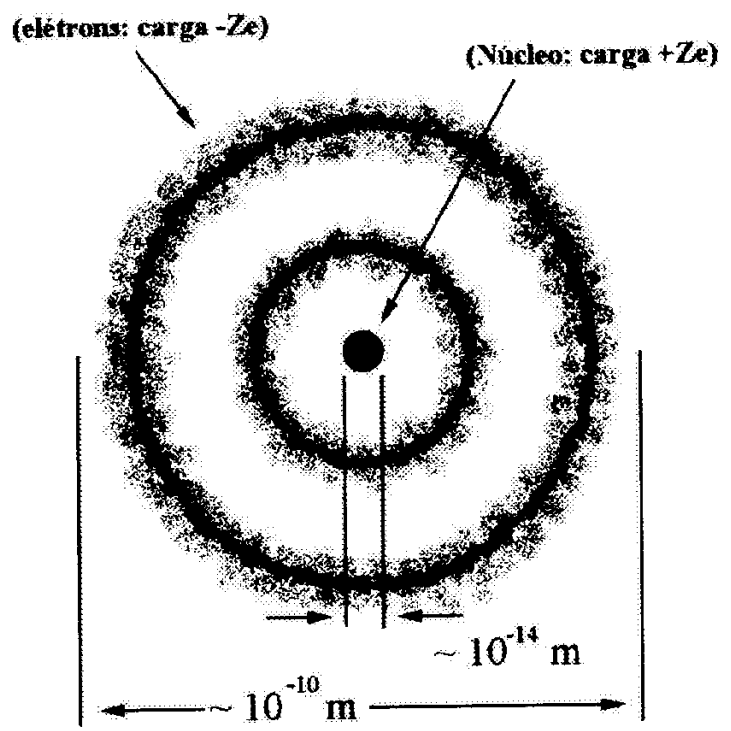

Figura 4. Esquema da distribuição de elétrons em um átomo.

Experimentos diversos revelam a existência de duas espécies de cargas elétricas, convencionadas de cargas elétricas positivas e cargas elétricas negativas. Estudos mais acurados revelam que a matéria é formada de pequenos tijolinhos, denominados átomos (Fig. 4). Os átomos constituem-se de prótons (com carga positiva e massa igual a $1,6725 \times 10^{-27} \mathrm{~kg}$ ), de elétrons (de carga absoluta igual à do próton mas negativa e de massa 1840 vezes menor que a massa do próton) e de nêutrons (com massa levemente maior que a do próton e sem carga).

\section{III.1.1 Lei de Coulomb}

Considerando-se a interação elétrica entre duas partículas eletricamente carregadas em repouso para um observador em um sistema de referência inercial, ou, quando muito, em movimento a baixa velocidade, os resultados constituem o que se chama de eletrostática. Essa interação é regida pela Lei de Coulomb, em homenagem ao engenheiro francês Charles A. de Coulomb (1736 - 1806), formulada como:

A interação eletrostática entre duas partículas carregadas é proporcional às suas cargas e ao inverso do quadrado da distância entre elas e tem a direção da reta que une as duas cargas.

Ou matematicamente:

$$
\vec{F}=\frac{1}{4 \pi \epsilon_{0}} \frac{q q^{\prime}}{r^{3}} \vec{r}
$$

em que $r$ é a distância entre as duas cargas $q$ e $q \prime, \vec{F}$ é a força que atua sobre qualquer das cargas e $\epsilon_{0}$ é a constante permissividade elétrica do vácuo.

Um aspecto interessante é que a carga elétrica não aparece com qualquer quantidade, porém apenas como um múltiplo de uma unidade fundamental $(e)$, ou quantum, cujo valor é $1,6021 \times 10^{-19} C$.

\section{III.1.2 Campo Elétrico}

Um conceito abstrato útil é o do campo elétrico, $\vec{E}$, produzido por uma carga em uma posição qualquer no espaço. Devido a esse campo, uma carga qualquer $(q \prime)$ colocada neste ponto sentiria a solicitação de uma força. Essa grandeza vetorial pode ser formulada como:

$$
\vec{E}=\frac{1}{4 \pi \epsilon_{0}} \frac{q}{r^{3}} \vec{r}
$$

O campo elétrico obedece o princípio da superposição linear, isto é:

$$
\vec{E}_{\text {total }}=\sum_{i} \vec{E}_{i}
$$

\section{III.1.3 Potencial elétrico}

Uma partícula eletricamente carregada, colocada em um campo elétrico, tem energia potencial devido à sua interação com o campo. O potencial elétrico $\phi$ em 
um ponto é definido como energia potencial por unidade de carga colocada no ponto.

Considerando-se a energia associada à configuração de uma partícula em um campo eletrostático, pode-se escrever que a variação do trabalho, $\delta W$, é dada por um produto escalar:

$$
\delta W=-\vec{F} \cdot d \vec{\ell}=-q \vec{E} \cdot d \vec{\ell}=q d \phi,
$$

em que $d \vec{\ell}$ é o caminho percorrido. Isso permite encontrar o potencial $\phi$ para uma carga $q$, i.e.,

$$
\phi=\frac{1}{4 \pi \epsilon_{0}} \frac{q}{r},
$$

o que é conveniente e sugestivo para o cálculo do potencial resultante para um conjunto de cargas, pois o potencial é um valor escalar, de mais fácil manuseio numérico. Explicita-se que o campo elétrico é dado pela variação máxima da taxa espacial do potencial elétrico e seu sentido é oposto à direção da máxima variação, ou seja:

$$
\vec{E}=-\nabla \phi
$$

\section{III.1.4 O fluxo elétrico e a Lei de Gauss}

Outro conceito muito útil é a Lei de Gauss.

O fluxo elétrico total através de uma superfície fechada é dada pela carga elétrica líquida total dentro dessa superfície.

$\mathrm{Na}$ forma integral:

$$
\psi=\oint \vec{E} \cdot \hat{n} d s=\frac{q_{\text {total }}}{\epsilon_{0}} .
$$

Na forma diferencial:

$$
\nabla \cdot \vec{E}=\frac{\rho_{\text {total }}}{\epsilon_{0}} .
$$

A combinação da Lei de Gauss com $\vec{E}=-\nabla \phi$ descreve todos os fenômenos eletrostáticos. Embora, em geral, sua aplicação não seja tarefa fácil ou sempre possível.

\section{III.1.5 Outras considerações relativas às pro- priedades elétricas}

Campos elétricos sobre e dentro de condutores elétricos - No interior dos condutores elétricos não haverá campo elétrico, pois as cargas movimentar-seão até estabelecer um mesmo potencial elétrico. Já na superfície, as cargas se ajustarão de forma a restar apenas a componente de campo elétrico normal à superfície. As cargas serão retidas na superfície e não sofrerão mais solicitação tangencial a ela. Esse é o princípio que rege a gaiola de Faraday, ou seja, uma superfície condutora hermeticamente fechada blinda o interior de um volume a campos elétricos externos.

Corrente elétrica - A intensidade de uma corrente elétrica é definida como a carga elétrica líquida que passa, por unidade de tempo, através de uma secção da região por onde ela flui. A sua formulação pode ser dada como:

$$
\mathcal{I}=\frac{\delta Q}{\delta t}
$$

em que $\mathcal{I}$ é a intensidade da corrente, $\delta Q$ a quantidade de carga e $\delta t$ o intervalo de tempo considerado. A corrente elétrica é expressa em coulombs/segundo ou $\mathrm{Cs}^{-1}$, designada ampère (unidade $A$ ) em homenagem ao físico francês André M. Ampère (1775-1836). Por razões históricas, o sentido de uma corrente elétrica está convencionado como sendo o do movimento das partículas carregadas positivamente. Trata-se do mesmo sentido do campo elétrico aplicado ou da queda de potencial que produz o movimento das partículas carregadas. Portanto, se a corrente é devida ao movimento das partículas carregadas negativamente, tais como os elétrons, o sentido da corrente é oposto ao movimento real dos elétrons.

Polarização da matérica - A polarização ocorre quando um agente leva uma porção da matéria a ter uma carga resultante em uma região e uma carga oposta em outra região deslocada relativamente a essa primeira região. A porção da matéria torna-se então um dipolo elétrico que tende a se orientar e mover na direção em que o campo cresce.

\section{III.1.6 As equações de Maxwell}

O entendimento mais elaborado do fenômeno dos campos elétricos e das descargas elétricas atmosféricas exige a consideração de grandezas com variação no tempo e a consideração de aspectos magnéticos. No entanto, tal detalhamento no formalismo não poderá ser realizado em espaço tão reduzido; o propósito é somente uma muito sucinta apresentação das equações do eletromagnetismo.

A intenção é informar que as equações de Maxwell, juntamente com condições de contorno e de informações do meio ambiente permitem uma descrição completa dos fenômenos eletrodinâmicos. Essas equações para o espaço livre são:

$$
\begin{aligned}
\nabla \cdot \vec{E} & =\frac{\rho}{\epsilon_{0}} \\
\nabla \cdot \vec{B} & =0 \\
\nabla \otimes \vec{E} & =-\frac{\partial \vec{B}}{\partial t}, \\
\nabla \otimes \vec{B} & =\mu_{0} \vec{J}+\frac{1}{c^{2}} \frac{\partial \vec{E}}{\partial t}
\end{aligned}
$$

em que $\rho$ é a densidade volumétrica de carga, em $C \mathrm{~m}^{-3}$; $\vec{J}$ é a densidade de corrente, em $A / \mathrm{m}^{2}$; e $c$ é a velocidade da luz no vácuo. A operação $\nabla \cdot \vec{A}$, onde $\vec{A}$ vetor qualquer, dá a idéia de um fluxo divergindo de ou convergindo para um ponto no espaço; enquanto $\nabla \otimes \vec{A}$ dá a idéia de uma circulação. 


\section{III.2 A natureza elétrica da atmosfera}

O termo eletricidade atmosférica nasceu do esforço primordial de estudar a componente eletrostática do campo geoeletromagnético.

Antes da era espacial, experimentos em balões indicavam a existência de um "capacitor atmosférico", constituído por uma eletrosfera $(70-150 \mathrm{~km}$ de altitude), a superfície condutora da Terra, e o ar entre essas "superfícies". Atualmente, pesquisa-se um sistema mais complexo, constituído de campos elétricos planetários (considerar um regime de baixas frequências). Como a atmosfera é eletricamente condutora, um campo elétrico, para ser mantido, deve ser provido por forças não-elétricas. Os mecanismos básicos são:

- Interação do vento solar com a magnetosfera;

- Interação dos ventos de maré com o plasma ionosférico na região do dínamo ionosférico;

- Tempestades elétricas na parte inferior da atmosfera.

\section{III.2.1 Campos elétricos planetários}

A estrutura elétrica que envolve a Terra caracterizase pela existência dos seguintes campos elétricos:

\section{Campo elétrico interplanetário}

O vento solar é basicamente um plasma permeado por um campo magnético. Um observador em movimento relativo a esse plasma sentirá o seguinte campo:

$$
\vec{E}=\vec{V} \otimes \vec{B}_{h}
$$

em que $\vec{V}$ é a velocidade relativa do observador com respeito ao plasma; $\vec{B}_{h}$ é o campo de indução magnética heliosférica.

2. Campo elétrico de convecção

O campo elétrico de convecção é um campo elétrico quase-estático e de grande escala que existe na magnetosfera terrestre.

Teorias propostas:

1. Arrasto viscoso do plasma da magnetosfera pelo vento solar. Isso cria um fluxo de plasma na cauda da magnetosfera, que origina um campo elétrico (Fig. 5):

$$
\vec{E}_{c v}=-\vec{V}_{c v} \otimes \vec{B}_{i}
$$

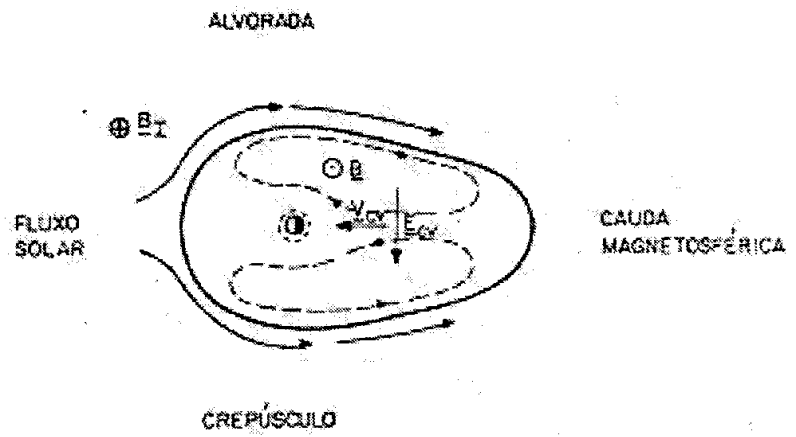

Figura 5. Esquematização do arrasto viscoso (vista de topo do Hemisfério Norte).

2. O processo de reconexão magnetosférica (fusão do campo geomagnético com o campo magnético interplanetário) permite a influência do campo elétrico interplanetário no interior da magnetosfera. Isso origina o movimento convectivo do plasma magnetosférico (Fig.6), regido por:

$$
\vec{E}_{i}=-\vec{V}_{s} \otimes \vec{B}_{i}
$$

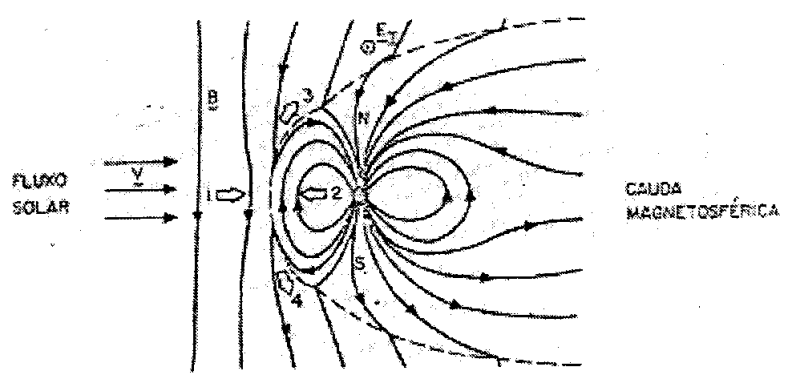

Figura 6. Esquematização do movimento convectivo do plasma magnetosférico (vista com um corte meridional).

Em períodos magneticamente calmos (índice geomagnético $k p \leq 2$ ), a magnitude do campo elétrico, $\|E\|$, é de aproximadamente $0,3 \mathrm{mV} / \mathrm{m}$ (milivolts/metro).

3. Campo elétrico de polarização:

À medida que o plasma da cauda aproxima-se da Terra, ganhando energia com o aumento da intensidade do campo geomagnético, a deriva devida ao gradiente de $B$ torna-se importante no movimento, de tal forma que as trajetórias de deriva de prótons e elétrons são separadas. Isso gera uma separação de cargas (constituindo a camada de Alfvén), que resulta em um campo elétrico. Esse campo elétrico é no sentido crepúsculo-alvorada, para blindar a plasmasfera do campo elétrico de convecção. A camada de Alfvén depende da condutividade da ionosfera e da energia das partículas que vêm da cauda. 


\section{Campo elétrico de penetração}

Este campo elétrico resulta do desbalanceamento do campo elétrico de convecção e do campo elétrico de polarização. O mecanismo de transferência para baixas latitudes não está ainda bem conhecido.

5. Campo elétrico de co-rotação:

Admitindo-se que a ionosfera é altamente condutora, rigidamente acoplada à atmosfera e envolvida por um plasma condutor, a configuração total do campo geomagnético tenderá a girar rigidamente com a Terra. Campos elétricos (e magnéticos) em sistemas referenciais de movimentos não-relativísticos são dados pela relação:

$$
\begin{aligned}
\vec{E}^{\star} & =\vec{E}+\vec{V} \otimes \vec{B}, \\
\vec{B}^{\star} & =\vec{B},
\end{aligned}
$$

em que o símbolo $\star$ refere-se ao sistema em movimento e a ausência desse símbolo identifica o sistema em repouso. A velocidade zonal é dada por:

$$
V_{\lambda}=\omega_{t} R \cos (\lambda)
$$

em que $\lambda$ é a latitude, $\omega_{t}$ é a velocidade angular de rotação, e $R$ a distância radial ao centro da Terra. Isso implica o campo elétrico de co-rotação:

$$
\vec{E}_{c}=-\omega_{t} R B \cos (\lambda) \hat{R},
$$

6. Campo elétrico do dínamo ionosférico (calmo e perturbado):

O dínamo ionosférico é conseqüência da influência do Sol e da Lua na atmosfera terrestre. O Sol atua basicamente por aquecimento da camada de ozônio e vapor d'água, e a Lua atua em função da atração gravitacional. O Sol e a Lua produzem forças oscilatórias na atmosfera com períodos de frações do dia solar (24h) e do dia lunar $(24,8 \mathrm{~h})$. Essas forças dão origem a movimentos do ar neutro (ventos de maré), fundamentalmente na direção horizontal. O movimento do ar através das linhas de campo geomagnético geram forças eletromotivas que produzem correntes elétricas (Fig. 7) em altitudes em que a condutividade elétrica é apreciável (principalmente na região $E$ ionosférica). Por causa das variações da condutividade na vertical e na horizontal, as correntes não podem fluir livremente em todas as direções e, deste modo, polarizações são estabelecidas. A região do dínamo estende-se praticamente de 90 a $150 \mathrm{~km}$ de altitude. A ordem de grandeza do campo elétrico é de $1 \mathrm{mV} / \mathrm{m}$. Quanto à intensidade relativa, $\left\|E_{\text {lunar }}\right\| \approx 5 \%$ da $\left\|E_{\text {solar }}\right\|$. Períodos magneticamente perturbados apresentam valores e comportamentos alterados de $E$. O dínamo perturbado é estabelecido pelas perturbações dos ventos termosféricos produzidos por aquecimento auroral.

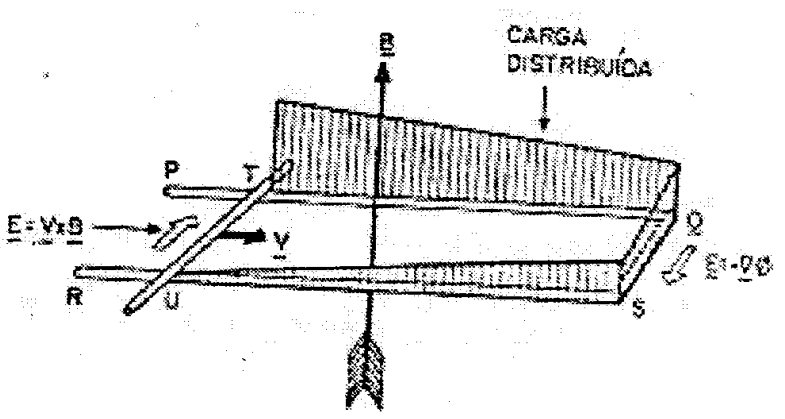

Figura 7. Dínamo ionosférico. Representação simplificada do mecanismo de fluxo de corrente do dínamo ionosférico.

7. Campo elétrico da baixa atmosfera:

$\mathrm{Na}$ baixa atmosfera (altitudes $\mathcal{H} \lesssim 70 \mathrm{~km}$ ), existe um campo elétrico quase-estacionário com sentido vertical e para baixo, que basicamente ocorre em regiões do céu limpo, denominado campo elétrico de tempo bom. A diferença de potencial entre a eletrosfera e a superfície da Terra é da ordem de $300 \mathrm{kV}$. A densidade de corrente elétrica é de aproximadamente $-2 \times 10^{-12} \mathrm{~A} / \mathrm{m}^{2}$ e a componente vertical do campo elétrico é, no solo, da ordem de $-100 \mathrm{~V} / \mathrm{m}$. Atribui-se às nuvens cumulonimbus, ocorrendo em várias regiões do globo terrestre, a razão para a manutenção dessa diferença constante de potencial. As Cumulonimbus são nuvens que se apresentam como estruturas elétricas intrínsecas, podendo conter cargas elétricas de elevado valor. Essa compreensão física leva à proposição do conceito de um circuito elétrico atmosférico global.

\section{Elementos do circuito elétrico atmosférico global}

A atmosfera da Terra mostra-se como um circuito elétrico complexo [5,6,7]. A parte desse circuito analisada aqui é a porção mais próxima da superfície $(\leq 150 \mathrm{~km})$. Essa região revela-se como um capacitor esférico, onde a ionosfera é a superfície externa carregada positivamente, enquanto a superfície da Terra é a esfera interna concêntrica à primeira, carregada negativamente, sendo a nuvem de tempestade o gerador que age no sentido de manter a carga negativa da esfera interna, contribuindo para a manutenção das cargas positivas na esfera externa. Essa idealização recebe a denominação de Circuito Elétrico Atmosférico Global, esquematizada na Fig. 8. 


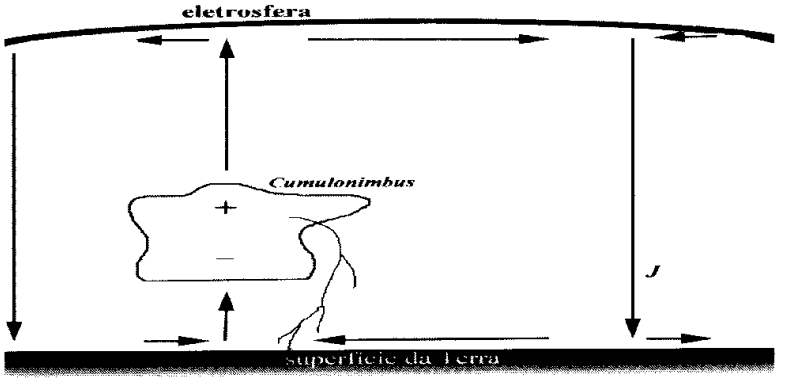

Figura 8. Circuito Elétrico Atmosférico Global.

A radiação eletromagnética incidente ioniza a atmosfera terrestre, definindo uma região altamente ionizada - a Ionosfera - , localizada aproximadamente entre 70 e $1000 \mathrm{~km}$. A Ionosfera mostra-se positivamente carregada e a superfície da Terra, negativamente, o que dá origem a um campo elétrico vertical apontando para baixo. O valor desse campo próximo ao solo é de cerca de $100 \mathrm{~V} / \mathrm{m}$. A atmosfera contida entre essas regiões é uma mistura homogênea de gases (Nitrogênio $\approx 75 \% \mathrm{e}$ Oxigênio $\approx 24 \%$ ), não constituindo um isolante elétrico perfeito. Esse relativo caráter condutor permite o fluxo de uma corrente elétrica de cima para baixo, de cerca de $2 \times 10^{-12} \mathrm{~A} / \mathrm{m}^{2}$, que integrada para toda a Terra, resulta uma corrente da ordem de $1 \mathrm{kA}$. Essa corrente elétrica de tempo bom anularia a diferença de potencial ionosfera-solo em um tempo estimado de $10 \mathrm{minu}-$ tos. No entanto, essa diferença de potencial se mantém, sendo as nuvens cumulonimbus identificadas como as principais responsáveis pela manutenção dos potenciais. Elas atuam como um gerador elétrico, recompondo as cargas na atmosfera. O relâmpago, ao mesmo tempo que é um efeito, também é um agente desse processo eletrodinâmico de transferência de cargas e de energias.

\section{IV.1 A eletrificação das nuvens}

A eletrificação das nuvens resulta da separação de cargas elétricas e sua segregação no espaço pelos movimentos do ar e de partículas supensas. Os mecanismos envolvidos nessa eletrificação apóiam-se nas teorias de carregamento por precipitação e por convecção. No entanto, o mecanismo que predomina ou a proporção com que cada um atua ainda não está definido. Para esse entendimento são necessárias pesquisas sobre vários parâmetros importantes, como campos elétricos, cargas elétricas, movimentos do ar, precipitação, comportamento dos relâmpagos, etc. Esse entendimento da eletrificação das nuvens depende da análise de aspectos macroscópicos e microscópicos e também dos desenvolvimentos dinâmicos.

\section{IV.1.1 Teorias para a eletrificação das nuvens}

Grosso modo, a estrutura elétrica das nuvens cumulonimbus pode ser caracterizada como um dipolo elétrico vertical com o centro de carga positiva principal na parte superior, acima de um centro de carga negativa. Há a proposição de um centro secundário de cargas positivas abaixo de centro de cargas negativas. Duas explicações para a criação e manutenção dessa estrutura elétrica são:

1. A hipótese da precipitação consiste na aquisição de cargas elétricas negativas por hidrometeoros e seu movimento descendente, devido à atuação gravitacional, com respeito às partículas menores (mais leves) positivamente carregadas. Nessa teoria, há dois mecanismos microscópicos de carregamento a serem investigados: (a) transferência de carga por indução elétrica e (b) transferência de carga por meio de colisões entre granizo, saraiva e cristais de gelo.

2. A hipótese da convecção consiste no transporte de cargas elétricas e seu acúmulo seletivo em regiões específicas da nuvem. As cargas elétricas poderiam ser provenientes do movimento convectivo das cargas espaciais do efeito corona (cargas liberadas na superfície pelo efeito das pontas) e/ou das cargas espaciais associadas aos meios com condutividades elétricas diferentes.

\section{IV.1.2 Outros aspectos da eletrificação das nu- vens}

A técnica de observação pelos radares doppler das Cumulonimbus revela-se útil para a identificação dos movimentos interiores nas nuvens. Busca-se relacionar os lugares de maior refletividade com aspectos da ocorrência de descargas elétricas (localização, taxa temporal, etc). De forma auxiliar, observações in situ contribuem para revelar a natureza, tamanho e quantidade de carga elétrica das nuvens e das precipitações. Outra técnica que permite completar a compreensão da eletrificação das nuvens é a investigação dos campos elétricos internos e nas vizinhanças das nuvens eletrificadas. No entanto, essas medições têm mostrado considerável variabilidade.

Em tempo bom, o campo elétrico está orientado verticalmente para baixo. Com a presença das Cumulonimbus, o campo apresenta uma variação associada a uma conformação multipolar de cargas. Próximo à superfície, em uma região delgada $(\mathcal{H} \lesssim 100 \mathrm{~m})$, as cargas espaciais, devido ao efeito corona afetam esse valor de campo elétrico. Campos elétricos horizontais transientes observados em baixo das Cumulonimbus têm sido atribuídos a cargas positivas depositadas nas precipitações pelos relâmpagos. Investigações experimentais revelam que o centro de carga negativo, na parte inferior da Cumulonimbus $\left(-3 \mathrm{a}-12^{\circ} \mathrm{C}\right)$, é mais definido e dispõe-se em uma distribuição mais horizontal. Já a carga positiva acima está mais difusa e estendida em altura. Evidências indicam a existência de uma camada 
de blindagem, isto é, cargas espaciais acumuladas, nas fronteiras da nuvem decorrente da mudança de condutividade do meio físico.

As emissões em rádio-freqüência associadas com a ruptura dielétrica e do processo de descarga elétrica na Cumulonimbus são observadas em uma parte ampla do espectro de radiação, de vários $\mathrm{kHz}$ a mais que $10 \mathrm{GHz}$. Os mecanismos propostos como produtores dessas emissões são:

1. aceleração das cargas na ponta dos canais em desenvolvimento;

2. tortuosidades de pequenas escalas do canal do relâmpago;

3. ramificações de pequena escala no desenvolvimento das estruturas do canal tanto dentro quanto fora da Cumulonimbus;

4. interações elétricas entre as partículas precipitantes.

Um dos interesses para a deteção dessas emissões é que elas permitem identificar as regiões fontes e investigar as estruturas elétricas e a propagação das descargas elétricas associadas às cumulonimbus.

Os trovões que acompanham os relâmpagos em uma nuvem cumulonimbus resultam da rápida expansão do ar aquecido na passagem da corrente elétrica. $\mathrm{O}$ som característico e variado desses trovões decorre da posição das partes do canal que o produzem, relativas ao observador; de características termodinâmicas da atmosfera; e de obstáculos à sua propagação. Para se estimar a distância (em quilômetros) de um relâmpago, uma regra prática é o observador em questão dividir o tempo decorrido entre o brilho percebido e o som ouvido por três (o tempo deve ser tomado em segundos). Em áreas abertas, esse procedimento pode auxiliá-lo a ter uma percepção mínima do perigo a que pode estar exposto.

\section{IV.1.3 Eletrificação de nuvens em outros plane- tas}

Evidências de relâmpagos têm sido identificadas na atmosfera tanto de Vênus quanto de Júpiter. Essas constatações se dão por meio do monitoramento de luminosidades transientes; de emissões eletromagnéticas; e da presença de ondas que afetam o comportamento de partículas elétricas ao longo de linhas de campo magnético planetário. A possibilidade de dispor de informações das condições ambientais planetárias e, assim, comparar as informações das descargas elétricas planetárias com os parâmetros terrestres é muito instigante para o conhecimento das estruturas de nuvem e das suas eletrificações. Nos próximos anos, essas informações planetárias deverão ser coletadas mais abundantemente. Pode-se antecipar que uma aplicação prática será testar os modelos físicos criados para estudar as tempestades severas na Terra.

\section{A física dos relâmpagos}

Com a possibilidade de detecção dos relâmpagos em bases contínuas, de forma mais eficiente, e geograficamente abrangentes, o fenômeno relâmpago começa a ganhar ênfase principalmente como um elemento traçador atmosférico, pois relaciona-se a características meteorológicas (por exemplo: profundidade da nuvens cumulonimbus) e a propriedades eletrodinâmicas da atmosfera (por exemplo: condutividade elétrica). Várias áreas de pesquisa (como a Física, as Ciências Espaciais, a Metereologia, a Engenharia Aplicada, etc.) têm desenvolvido novos planos de investigação, pois esse fenômeno, que se acreditava algo bem conhecido, tem revelado aspectos inusitados (ver a Secção V). Aumentaram, assim, as motivações para pesquisas de detecção conjuntas com radares, satélites, monitoramento observacional de superfície, etc. A possibilidade de uso inclui análises da evolução das tempestades, severidade, o desenvolvimento de modelagens, etc.

Os relâmpagos têm uma grande importância na natureza e no ambiente humano, fomentando pesquisas sobre o circuito elétrico atmosférico global e, particularmente, sobre as atividades elétricas das nuvens cumulonimbus. Ênfase maior é dada à investigação dos mecanismos elétricos e dos processos eletrodinâmicos relacionados aos relâmpagos devido ao propósito de aplicações tecnológicas e de segurança, pois essas descargas transportam grande quantidade de energia e causam efeitos eletromagnéticos, destruições e mortes. Pela sua localização geográfica e extensão territorial, o Brasil apresenta grande ocorrência de relâmpagos, propiciando condições de um imenso laboratório natural.

\section{IV.2.1 Aspecto histórico}

A mais antiga referência científica identificando a existência de uma eletricidade atmosférica e sua relação com os relâmpagos parece ser de 1708. Após isso, esse interesse começou a se especializar.

Muitos pensam que foi o filósofo e cientista norteamericano Benjamin Franklin a primeira pessoa a realizar um experimento em que se observasse fagulhas devidas à eletricidade associada às nuvens. Ele foi precedido pelo pesquisador francês D'Alibard (1752). Um mês depois, em vez de usar uma haste metálica com um fio aterrado como no experimento francês, Benjamin Franklin obteve sucesso empinando um papagaio. Isso permitiu estabelecer cientificamente a presença de eletricidade nas nuvens de tempestade. Franklin sugeriu o uso de condutores para a prevenção da descarga elétrica. Em prosseguimento a esses estudos, de forma independente, os pesquisadores Lemonnier e De Romas demonstraram a presença de um campo elétrico mesmo em tempo bom [8]. 
Esses resultados evidenciaram a eletricidade associada a nuvens cumulonimbus, a possibilidade de se construir um caminho condutor para escoamento da descarga elétrica e a existência de um regime de campo elétrico na atmosfera. Isso criou toda uma área nova de estudos nas geociências, pois, além da curiosidade científica, essa se revelava um assunto preocupante pelos efeitos danosos do fenômeno.

\section{IV.2.2 O relâmpago}

De uma forma geral, os relâmpagos consistem de uma descarga elétrica transiente de elevada corrente elétrica através da atmosfera. Em geral, essas descargas são conseqüências das cargas elétricas acumuladas $(\approx 10-100 \mathrm{C}$ ) nas cumulonimbus e ocorrem quando o campo elétrico excede localmente o isolamento dielétrico do ar $(>400 \mathrm{kV} / \mathrm{m})$.

Os relâmpagos podem ser classificados quanto à (a) origem e configuração, (b) multiplicidade (número de descargas que o constitui), e (c) sua polaridade (carga elétrica associada).

Quanto à forma de ocorrência e configuração (a), os relâmpagos classificam-se em relâmpagos nuvem-solo, solo-nuvem, entre-nuvens, intranuvens, horizontais (ao projetarem-se e terminarem como que no espaço vazio lateral à nuvem), e para a estratosfera (Fig. 9).

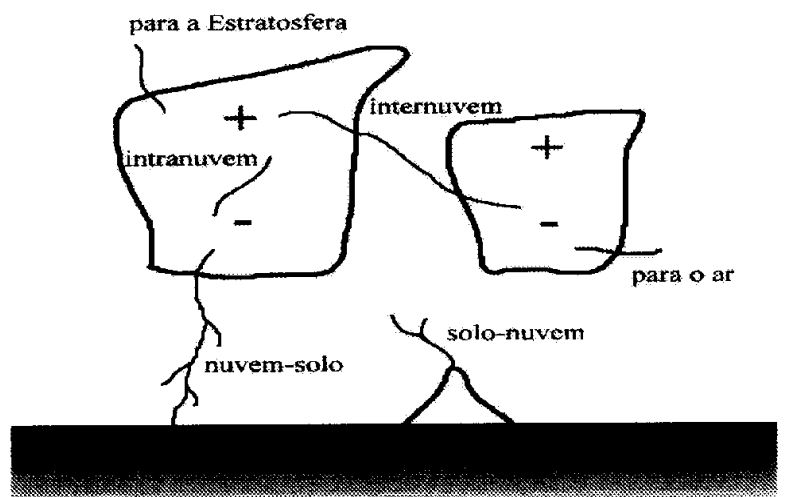

Figura 9. Classificação dos relâmpagos quanto à forma de ocorrência. Uma visão simplificada da classificação dos relâmpagos quanto à forma de ocorrência.

Embora não sejam os mais abundantes, os relâmpagos nuvem-solo eram anteriormente os que mereciam maior atenção nas pesquisas, devido aos prejuízos materiais que causavam ou aos riscos à vida que infligiam. No entanto, devido aos avanços tecnológicos que tornaram, por exemplo, as aeronáveis mais suscetíveis à influência elétrica ou eletromagnética, todas as formas de manifestação começam a receber igual atenção. As outras formas não são tão bem conhecidas quanto as nuvem-solo.

Quanto à multiplicidade (b), os relâmpagos nuvemsolo são formados, em geral, de uma única descarga elétrica (denominada descarga de retorno); porém podem apresentar-se constituídos de múltiplas descargas consecutivas. Tais descargas perduram por $\approx 10-200$ microssegundos e apresentam-se separadas no tempo por um intervalo aproximado de 3 a 500 milissegundos, cujo valor típico é em torno de 40 milissegundos.

Quanto à polaridade, um relâmpago que se inicia em uma região de cargas negativas é definido como um relâmpago de polaridade negativa; se em carga positiva, um relâmpago positivo; e se apresenta descargas múltiplas com ambas polaridades, um relâmpago bipolar. O processo físico associado à manifestação de polaridade é mais sutil do que se pode perceber inicialmente, devido à ignorância de detalhes físicos do transporte de cargas, traduzida vagamente nas expressões "transporte de cargas efetivo", "redução de cargas efetiva", "neutralização de cargas efetiva" ou "transporte de cargas efetivo".

\section{IV.2.3 Análise de um relâmpago nuvem-solo negativo}

De uma forma geral, parece ocorrer uma ruptura dielétrica preliminar na parte baixa da nuvem; seguese o desenvolvimento de um líder escalonado (descarga que precede e cria o canal do relâmpago); próximo ao solo ascende uma descarga conectante, que completa o canal; e resulta então uma descarga de retorno, de neutralização das cargas. Em geral, quando ocorrem descargas subsequentes, as descargas de retorno são iniciadas por um líder contínuo e poucas vezes com ramificação. Algumas vezes, uma corrente contínua sustenta-se pelo canal ionizado. O aumento da luminosidade do canal acompanhado por uma rápida variação do campo elétrico, que às vezes acontece, é denominado componente $M$. $\mathrm{O}$ denominado processo $K$ é geralmente interpretado, embora existam controvérsias, como uma pequena descarga de retorno que ocorre quando a descarga propagante, dentro da nuvem, encontra um bolsão de cargas de sinal oposto. O processo $J$ seria uma lenta descarga propagante que iniciou o processo K.

A física da ruptura dielétrica preliminar ainda não é entendida, se é que há um único e bem identificado evento.

O líder escalonado move-se a passos sucessivos de 10 a 200 m de comprimento, com um valor típico de $50 \mathrm{~m}$. Existem pausas entre os passos de aproximadamente 50 microssegundos, variando de 30 a 120 microssegundos. A velocidade do líder varia de $10^{5}$ a $3 \times 10^{6} \mathrm{~m} / \mathrm{s}$, com um valor típico de $3 \times 10^{5} \mathrm{~m} / \mathrm{s}$. Podem ocorrer 100 ou mais passos e o líder dispende em torno de 10 milissegundos para alcançar o solo partindo da base da nuvem. A carga do líder está contida em um canal com o diâmetro de 1 a 10 m e apresentando uma densidade de carga distribuída quase uniformemente, valor em torno de $10^{-3} \mathrm{C} / \mathrm{m}$. A densidade de carga dos líderes escalonados é altamente variável e estimada no intervalo de $10^{-5}$ a $2 \times 10^{-3} \mathrm{C} / \mathrm{m}$. Durante o processo, de uns poucos coulombs a dezenas de coulombs 
de carga negativa são distribuídos ao longo do canal, que são neutralizados pela descarga de retorno.

A descarga conectante surge quando o líder escalonado aproxima-se de algum objeto condutor, tal como uma árvore, um monte de terra, a torre de uma linha de transmissão, etc., pois o campo elétrico produzido pela carga no líder pode ser intensificado pelo objeto e dar origem a uma descarga a partir do objeto. Nesse instante o circuito elétrico é formado e uma descarga de retorno tem origem, "escoando" ou "neutralizando" a carga elétrica associada ao canal.

\section{IV.2.3 Considerações sobre a nomenclatura}

Em geral, o domínio de um tópico de pesquisa está associado a uma nomenclatura clara, consistente e completa. A falta dessa nomenclatura no vernáculo ou traduz uma fenomenologia nova ou lacunas nas investigações de uma comunidade científica. Como designações básicas no Brasil, relacionam-se:

Relâmpago: designação do processo de descargas atmosféricas completo.

Raio: designação coloquial para o caminho luminoso da descarga atmosférica, às vezes utilizada, mais formalmente, para designar uma descarga para o solo.

Trovão: designação do efeito sonoro da descarga elétrica atmosférica, devida à expansão abrupta do ar aquecido pela decarga.

No entanto, há uma nomenclatura mais extensa na literatura internacional, em geral de caráter analógico, para as manifestações dos relâmpagos e muitas ainda sem equivalentes no vernáculo. Isso é conseqüência da falta ou da pouca observação visual do fenômeno no Brasil e de uma documentação sistematizada. Apresentam-se, a seguir, alguns termos usados:

Descarga aérea: uma descarga que não se conecta ao solo.

Sheet lightning: relâmpago que visualmente se mostra laminar.

Heat lightning: relâmpago que não é visto ou ouvido devido à distância da cumulonimbus e seria uma ocorrência comum durante o verão.

Rocket lightning: uma longa descarga aérea que lembra o trajeto de um foguete no céu.

Spider lightning: um relâmpago aéreo longo apresentando múltiplas ramificações (relâmpago aranha). Presente freqüentemente sob nuvens estratiformes tais como as que acompanham sistemas convectivos de mesoescala.
Forked lightning: relâmpago nuvem-solo que se abre em ramificações que se conectam ao solo.

Ribbon lightning: relâmpagos de múltiplas descargas em que elas ocorrem em posições levemente alteradas devido ao vento.

Bead lightning: relâmpago que se mostra com alternância ao longo do canal de regiões claras e escuras, como se fossem contas em um colar.

Ball lightning: relâmpago-bola é o relâmpago de forma aproximadamente esférica que desloca pela atmosfera, aparentemente desconectado de uma fonte de carga. Não há uma prova visual inequí voca da sua ocorrência, embora sejam muitos os relatos. As explicações físicas ainda estão sendo discutidas.

Quanto à categoria dos relâmpagos em conexão com o solo, eles podem ser classificados como:

Relâmpagos naturais: relâmpagos que ocorrem sem envolver nenhuma estrutura ou intervenção humana.

Relâmpagos artificialmente induzidos: relâmpagos que ocorrem devido a estruturas construídas ou por intervenção humana, como, por exemplo, relâmpagos associados a estruturas artificiais muito altas, a aeroplanos e a foguetes.

\section{Assuntos de pesquisa da eletrodinâmica atmosférica}

O campo de pesquisa sobre as descargas elétricas atmosféricas tem-se demonstrado muito rico de abordagens e promissor em termos de aplicações [9-13,7]. O ensino dessa área de ciência no Brasil precisa ser menos equivocado no entendimento dos fenômenos (como, por exemplo, em livros escolares, a afirmação incorreta de que os relâmpagos surgem da colisão de nuvens), mais apto na apropriação dos temas e mais pronto nos desenvolvimentos. Para isso, alguns tópicos de pesquisas recentes serão relacionados, com o fim de motivarem pesquisas inovadoras e essas serem de auxílio ao desenvolvimento de domínio técnico-científico.

\section{V.1 Modelos para a eletrodinâmica at- mosférica}

Nos últimos 30 anos, inúmeros modelos têm sido desenvolvidos para entendimento do comportamento eletrodinâmico atmosférico concernente ao $C E A G$. Entre esses modelos, alguns lidam com situações específicas e buscam analisar a distribuição de cargas, os campos elétricos e os relâmpagos.

\section{V.1.1 Elementos básicos da simulação de relâmpagos}


Em geral, para a obtenção de um modelo para a trajetória e comportamento do relâmpago, assume-se que o Líder Escalonado progride na direção do campo elétrico ( $-\nabla \phi$, que é o gradiente do potencial elétrico) existente na frente desse líder. De acordo com o grau de complicação e realismo da simulação numérica, fazem-se aproximações no formalismo adotado. Considerando-se que os campos magnéticos gerados possam ser desconsiderados, que a condutividade elétrica da atmosfera $\sigma$ é uma grandeza escalar e que cresce exponencialmente com a altura, que a corrente elétrica obedece à lei de Ohm simplificada, e tendo a ionosfera e o solo como condições de fronteiras, tem-se a seguinte equação para o potencial escalar:

$$
\frac{1}{T_{c}} \nabla^{2} \phi-\frac{\sigma}{\epsilon_{0}}\left(\nabla^{2} \phi+2 K \frac{\partial \phi}{\partial z}\right)=\frac{1}{\epsilon_{0}} \nabla \cdot J_{s}
$$

em que

\section{$T_{c}$ tempo característico do processo;}

$\epsilon_{0}$ permissividade elétrica do espaço livre;

$\frac{\sigma}{\epsilon_{0}}$ tempo de relaxação elétrico do ar;

$K$ constante que representa escala de altura da condutividade elétrica;

$J_{s}$ densidade superficial de corrente das cargas fontes.

Esse potencial permitirá determinar o campo elétrico $\vec{E}=-\nabla \phi$.

Os relâmpagos acontecem em um tempo característico $\tau_{c}$ muito pequeno $(<1 \mathrm{~s})$; assim, em uma simplificação, só o primeiro termo do lado esquerdo da Equação 21 precisa ser considerado. A equação resultante é a solução coulombiana. A esta solução adicionase a solução da Equação 21 antes da ocorrência da descarga elétrica, como uma condição inicial, que corresponde ao processo de separação de cargas na nuvem. Esta condição inicial é obtida considerando-se apenas o segundo termo do lado esquerdo da Equação 21. Esta solução combinada permite estabelecer uma análise eletrodinâmica da atmosfera e, em particular, simular a trajetória do relâmpago.

\section{V.1.2 Modelos eletrodinâmicos}

Os difentes modelos para a eletrodinâmica atmosférica são apresentados a seguir.

O trabalho desenvolvido por Anderson and Freier, em 1969, estabeleceu o formalismo teórico (como na Secção V.1.1) necessário para estudar a trajetória do relâmpago na atmosfera. Considerando-se as rápidas alterações associadas ao relâmpago comparadas com a situação quase estacionária da atmosfera, nesse trabalho obtiveram-se as distribuições de potencial para um dipolo vertical com uma atmosfera com condutividade constante com a altura e com uma condutividade que aumentava exponencialmente com a altura. Também se analisaram as mudanças de potencial elétrico durante a ascensão das cargas positivas da parte baixa da atmosfera, que eventualmente neutralizam as cargas do centro positivo menor na base da nuvem. Com esse modelo obteve-se um mecanismo convectivo que explicava o carregamento regenerativo da cumulonimbus.

Takagi e colegas, em 1986, consideraram uma configuração vertical e inclinada para o dipolo elétrico das cumulonimbus. Eles calcularam a proporção de descargas positivas com relação ao total delas. Nesse modelo, considerou-se que o líder escalonado inicia-se em um cilindro infinito de cargas e progride na direção do gradiente na ponta da descarga, em uma atmosfera de condutividade elétrica constante. Conseguiu-se, assim, um mecanismo que explicava as altas percentagens de relâmpagos em latitudes médias do Hemisfério Norte.

Dellera e Garbagnati, em 1982, consideraram o relâmpago a aproximadamente $1 \mathrm{~km}$ acima do ponto de incidência no solo. Analisaram-se a propagação dos canais inicialmente verticais de relâmpagos negativos e o início e a propagação de canais ascendentes positivos (descargas conectantes) a partir de estruturas elevadas no solo. Usaramu-se um anel unipolar de cargas para modelo da nuvem, segmentos lineares de cargas para os canais descendentes e ascendentes, e cargas pontuais ou lineares para as estruturas aterradas. Esse foi um estudo voltado às aplicações de engenharia elétrica.

Kawasaki e colegas, em 1989, aplicaram uma análise fractal e implementaram o modelo de Dellera e Garbagnati, considerando uma certa tortuosidade e ramificação como características representativas do canal do relâmpago. Esses trabalhos permitiram avaliar a exposição de estruturas localizadas em regiões planas e em condições orográficas mais complicadas.

Takeuti e colegas, em 1993, apresentaram uma abordagem empírica diferente para calcular o caminho do relâmpago na atmosfera. Não se considerou a natureza elétrica do fenômeno; porém uma natureza estatística. Desenvolveu-se um tratamento estatístico em que o caminho do relâmpago, abaixo da nuvem até o solo, é modelado com base na análise de fotografias. Esse trabalho analisou a eficiência de blindagens por estruturas elevadas, como torres metálicas.

Mendes e colegas, em 1996, desenvolveram um modelo similar ao modelo de Takagi; porém considerando condições mais realistas. Utilizaram-se esferas finitas de carga para modelo da nuvem e uma condutividade elétrica exponencialmente crescente com a altura na atmosfera. Esse trabalho mostrou que essa condutividade, de acordo com os modelos padronizados de atmosfera, também controla a ocorrência de relâmpagos positivos para o solo. Há um aumento de percentagem mesmo para dipolos verticais. Esses resultados 
numéricos estão em concordância com os valores experimentais obtidos no Brasil. Assim, esse trabalho estende os resultados do modelo de Takagi e colegas (inclui o Hemisfério Sul) e explica o comportamento das descargas para latitudes mais baixas. A Fig.10 apresenta um esquema da simulação do líder escalonado.

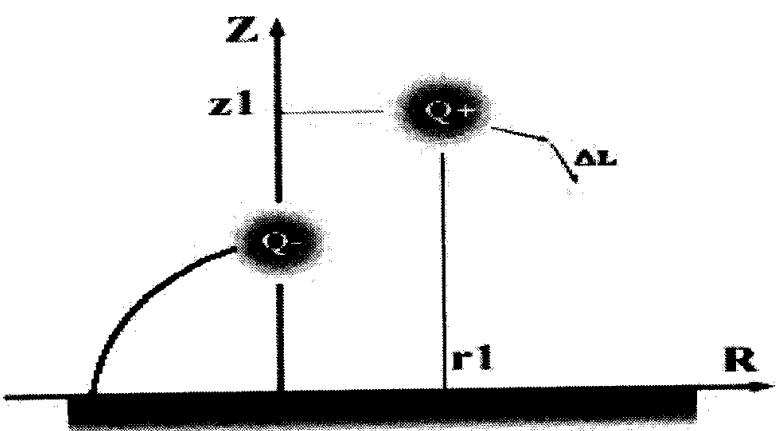

Figura 10. Esquema de simulação do lider escalonado.

Tais modelos, considerando-se suas bases teóricas e experimentais e levando-se em conta suas características distintas, apontam para a conveniência e a viabilidade de se buscar modelos eletrodinâmicos cada vez mais realistas. Além de permitir uma melhor compreensão científica do fenômeno, os modelos poderão ser de grande utilidade prática em termos de engenharia e de segurança.

\section{V.2 O acoplamento eletrodinâmico da at- mosfera}

A comunidade científica foi surpreendida, por meio de evidências irrefutáveis, com o acoplamento ativo da troposfera com a média e alta atmosferas. Embora desde 1886 existissem testemunhos, relatados em revistas de meteorologias, de fenômenos que ocorriam de forma estranha nas tempestades elétricas, somente em 1989 um golpe de sorte durante o teste de uma câmera sensível a baixa luminosidade, que iria voar em um foguete, colocou em discussão o balanço real de energia entre as regiões da atmosfera.

Cientistas da Universidade de Minnesota, USA, liderados pelo Geofísico Espacial Dr. John R. Winckler, documentaram um estranho brilho ocorrendo acima de cumulonimbus. Era o início de uma pesquisa sobre um fenômeno que não parecia ser um mero relâmpago, mas que estava associado às tempestades elétricas.

Atualmente, um variado conjunto de fenômenos luminosos transientes associados a relâmpagos, ou, no mínimo, às tempestades elétricas, foi identificado. Até o momento, esses eventos estão classificados em: sprites, jatos azuis, elves, halos de sprites, trolls e surtos de raios gama. A Fig. 11 apresenta, de forma esquemática, exemplos dos eventos luminosos associados às tempestades elétricas.

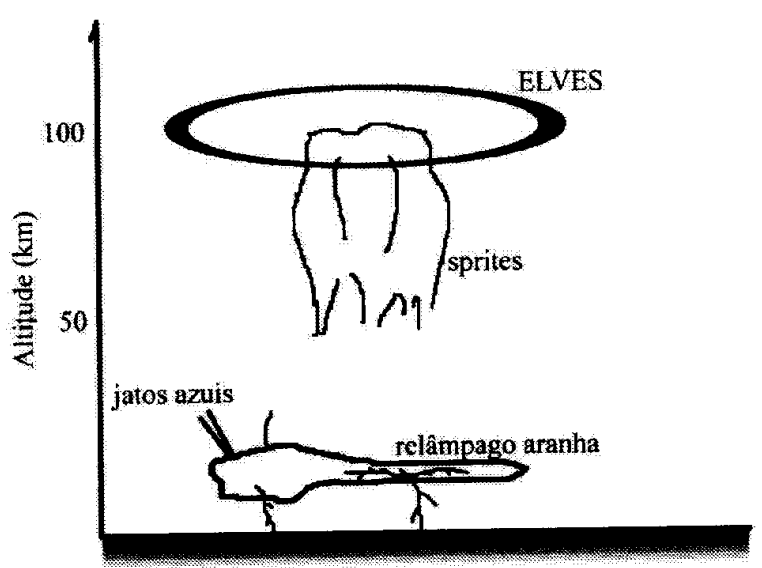

Figura 11. Exemplos de eventos luminosos associados a tempestades elétricas.

\section{V.2.1 Os eventos luminosos transientes}

Sprites: Os Sprites ou red sprites são fenômenos luminosos que podem se estender de $95 \mathrm{~km}$ até menos que $30 \mathrm{~km}$ de altitude. Análises indicam que eles iniciam usualmente entre 70 e $75 \mathrm{~km}$, desenvolvendo, em ambas as direções, velocidade de $\approx 10^{7} \mathrm{~m} / \mathrm{s}$. Eles perduram por dezenas de milissegundos; embora os elementos mais brilhantes durem apenas poucos milissegundos. Os sprites quase sempre seguem relâmpagos nuvem-solo de polaridade positiva, dentro de uma defasagem temporal de menos que $1 \mathrm{~s}$ a mais que $100 \mathrm{~ms}$. Esse fenômeno tem ocorrido tipicamente associado com amplas tempestades elétricas, especialmente naquelas que apresentam uma substancial região de precipitação estratiforme.

Elves: Os elves são percebidos como estruturas quasetoroidais em expansão. Documentou-se o seu alargamento horizontal e também uma expansão para baixo. É um fenômeno relativamente brilhante $(1000 \mathrm{kR})$ e de duração menor do que $500 \mathrm{~ms}$. Eles seguem por aproximadamente 300 ms com respeito a relâmpagos nuvem-solo intensos (corrente elétrica $>100 \mathrm{kA}$ ), a maioria com polaridade positiva. A teoria proposta para seu mecanismo é que os pulsos eletromagnéticos dos relâmpagos induzem um brilho transiente na ionosfera entre as altitudes de 80 e $100 \mathrm{~km}$.

Halo de sprites: Os halos de sprites parecem ser um brilho difuso na forma de disco que precedem os sprites, duram em torno de um milissegundo e lembram superficialmente os elves. Apresentam estruturas usualmente menores do que $100 \mathrm{~km} \mathrm{e}$ propagam-se para baixo de $\approx 85 \mathrm{a} \approx 70 \mathrm{~km}$. Os elementos do sprite parecem emergir da porção inferior do disco côncavo dos halos. 
Jatos azuis: Os jatos azuis são jatos de luz que emergem do topo de tempestades eletricamente ativas. Propagam para cima com velocidades $\mathrm{de} \approx 100 \mathrm{~km} / \mathrm{s}$, atingindo altitudes terminais de $\approx 40 \mathrm{~km}$. Seu brilho estimado é da ordem de $1000 \mathrm{kR}$. Esses jatos não parecem associar-se a relâmpagos nuvem-solo específicos; no entanto, a atividade elétrica parece cessar por alguns segundos após a ocorrência de um jato azul. Examinase a associação com tempestades que produzem granizo.

Trolls: Os trolls lembram superficialmente os jatos azuis, embora claramente dominados por uma emissão avermelhada. Eles parecem ocorrer após um sprite intenso cujas ramificações estenderamse para baixo até o topo das nuvens. Os trolls exibem uma luminosa "cabeça" à frente de uma "cauda" de luminosa fraca e movem-se para cima inicialmente $\mathrm{a} \approx 150 \mathrm{~km} / \mathrm{s}$, desacelerandose gradualmente, e desaparecendo em torno de 50 $\mathrm{km}$.

Surtos de Raios Gama: Surtos de Raios gama têm sido observados no solo durante tempestades elétricas. Têm sido percebidos 2 tipos de eventos. Um deles mostra um lento aumento de radiação, com fótons de energias até $3 \mathrm{MeV}$, e dura por uma hora ou mais antes de decair lentamente. A causa sugerida são os aerossóis radiativos nas partículas precipitantes na chuva. Superposto a essa radiação gradual há um surto impulsivo de fótons de mais alta energia (até $10 \mathrm{MeV}$ ), que perdura por uns poucos minutos. Sugere-se que esses raios gama são provenientes de radiação de frenagem de elétrons de maior energia colidindo com os átomos da atmosfera. O mecanismo seria a aceleração de elétrons pelos fortes campos elétricos estabelecidos durante as tempestades elétricas.

As investigações experimentais têm mostrado que esses fenômenos parecem associados com várias espécies de tempestades elétricas, produzidas em grandes Sistemas Convectivos de Mesoescala nas médias latitudes, linhas de instabilidades associadas a tornados, convecções tropicais profundas, ciclones, e "winter snow squalls".

\section{V.3 Técnicas de observação e medição}

Atualmente, para a coleta de informações experimentais da atmosfera associadas às condições de tempo, disseminam-se metodologias e recursos para o monitoramento extensivo e intensivo da atividade elétrica atmosférica. Inúmeras questões relativas às metodologias e técnicas de deteção e de medição de atividade elétrica na atmosfera baixa $(\lesssim 150 \mathrm{~km})$ precisam ser pesquisadas, de forma a permitir aplicações práticas (como por exemplo: as previsões de tempestades severas).

Quanto aos sistemas de estudo das atividades elétricas, podem-se relacionar:

- Sistemas de detecção e rastreio de relâmpagos.

Esses sistemas produzem informações de localização, intensidade, polaridade das descargas elétricas do tipo nuvem-solo. Atualmente existem também formas de se identificar descargas do tipo internuvens e intranuvens. Esse tipo de informação pode auxiliar na previsão a curtíssimo prazo das descargas nuvem-solo e de condições severas.

- Sistemas de imageamento de fenômenos atmosféricos (nuvens, relâmpagos, sprites, e outros fenômenos ópticos transientes).

Esses sistemas são compostos de um conjunto de câmeras CCDs convencionais e outro de câmeras CCDs de alta resolução espacial e temporal (da ordem de milissegundos). Este tipo de sistema permite avaliar o processo físico da formação das tempestades de uma forma contínua, desde o desenvolvimento das nuvens cumulonimbus até o seu estágio de dissipação. Além disso, esse tipo de método permite estudar e analisar de uma forma não induzida as características físicas dos relâmpagos como tortuosidade do canal, multiplicidade, intervalo entre descargas, entre outras, associadas a parâmetros físicos da atmosfera.

- Sistemas de monitoramento acústico da atividade elétrica, em especial do trovão.

Esses sistemas possibilitam avaliar efeitos de ondas de choque e propagação do som na camada atmosférica, que estão associados aos parâmetros físicos, químicos e elétricos da atmosfera local.

- Sistemas de monitoramento do campo elétrico atmosférico ( $\mathrm{AC} / \mathrm{DC})$.

Esses sistemas (detectores field mill, detectores de sferics e detectores similares) permitem monitorar continuamente parâmetros físicos da atmosfera local.

- Sistemas de integração das informações elétricas às demais informações atmosféricas.

Esses sistemas para integração e processamento de informações começam a ser discutidos e desenvolvidos. O propósito é não apenas permitir atender as pesquisas científicas, mas também serviços em tempo real. 
Acrescentam-se ainda outras tecnologias recémaprimoradas recentes de monitoramento com o uso de satélites. Possibilidades que vêm incorporar-se aos radares tipo Doppler e polarimétricos, que permitem análises de severidade do tempo.

Os sistemas de detecção e localização de relâmpagos baseiam-se em alguns princípios simples, mas sofisticados tecnologicamente para a sua operação otimizada. Apresentam-se sucintamente essas metodologias de detecção:

\section{- Método de Localização Direcional}

Esse tipo de sistema emprega dois ou mais sensores que medem o ângulo azimutal entre o sensor e a descarga elétrica, na verdade, o sinal decorrente da descarga de retorno. Esse ângulo é tipicamente determinado por meio do uso de 2 anéis (loops) de antenas magnéticas ortogonais. Quando 3 ou mais sensores são utilizados, um procedimento de otimização que minimiza os erros no ângulo pode ser empregado. Na realidade, esse sistema baseia-se no procedimento de triangulação.

\section{- Método do Tempo de Chegada}

No método do tempo de chegada do sinal eletromagnético (time-of-arrival method), 3 ou mais sensores que medem o tempo de chegada do sinal da descarga elétrica são empregados. Os sensores medem a diferença de tempo que o sinal eletromagnético leva para chegar até os vários sensores empregados. Com esse método, cada par de sensores fornece uma curva hiperbólica que descreve o conjunto de localizações que satisfazem a diferença de tempo medida. Havendo duas dessas curvas determinadas por 3 ou mais sensores desse tipo, é possível determinar uma posição a partir da intersecção das mesmas. Alguma ambiguidade geométrica eventual pode ser resolvida com a utilização de pelo menos 4 sensores.

\section{- Método IMPACT}

O método da Precisão Aumentada por Tecnologia Combinada (Improved Accuracy from Combined Technology - IMPACT) é a combinação do método do tempo de chegada e do método de localização direcional. Nesse novo arranjo o localizador direcional fornece a informação azimutal e o tempo absoluto de chegada informa sobre o alcance.

\section{- Método de Interferometria}

O método de interferometria baseia-se na característica eletromagnética do sinal e determina pela intensidade e fase, por meio de uma rede de sensores, a localização espaço-temporal da fonte do sinal. Esse método é capaz de discriminar as descargas que conectam o solo e as que não conectam.
Recentemente, alguns outros métodos começaram a ser implementados. Um é o sistema de mapeamento tridimensional de relâmpagos baseado em GPS (Global Positoning System). As medições servem não apenas para estudar as eletrificações das tempestades mas também como um valioso indicador da estrutura e intensidade das tempestades. Um outro é uma rede mundial de 7 magnetômetros de alta precisão sincronizados temporalmente. Esse sistema permitirá triangular cada evento de relâmpago no globo terrestre, com o fim de monitorar a evolução temporal e espacial da atividade global de relâmpagos.

\section{Conclusão}

A Eletrodinâmica Planetária constitui-se em uma área interdisciplinar de grande interesse teórico e prático. O desenvolvimento dessas pesquisas resultam em múltiplos benefícios para a sociedade brasileira. Alguns a curto prazo, como o desenvolvimento de metodologias avançadas e tecnologias de ponta, e outros de mais longa maturação, como a formação multidisciplinar de profissionais de diversas áreas. Este desenvolvimento requer (a) o engajamento dos professores, dos vários níveis de ensino, na administração competente de um conteúdo científico amplo, (b) a informação dos pesquisadores da importância e multiplicidade de enfoques dessa pesquisa, e (c) a formação de novos estudantes com a capacidade de atuar em áreas interdisciplinares (integrando potencialmente as áreas de física, meteorologia, matemática, computação, engenharia, química e biologia).

\section{Agradecimentos}

Os autores agradecem à FAPESP o suporte financeiro dado às pesquisas do Projeto Via-Lux (FAPESP 1998/3860-9).

\section{Referências}

[1] O. Jr. Mendes. A origem interplanetária e o desenvolvimento da fase principal das tempestades geomagnéticas moderadas (1978-1979). PhD thesis, Instituto Nacional de Pesquisas Espaciais, São José dos Campos, São Paulo, August 1992 (INPE-5445-TDI/491).

[2] S.I. Akassofu, "The solar wind-magnetosphere energy coupling and magnetospheric disturbances", Planetary Space Science, 28, 495-509 (1980).

[3] J.D. Jackson, Classical Eletrodynamics, John Wiley \& Sons, New York, 1965, 641

[4] O. Mendes Jr., "Estudo sobre os campos elétricos plasmasféricos e suas influências sobre a dinâmica das partículas carregadas", Master's thesis, Instituto Nacional de Pesquisas Espaciais, São José dos Campos, São Paulo, Sep, 1985. (INPE-3849-TDI/214). 
[5] H. Volland, Atmospheric Electrodynamics, SpringerVerlag, New York, 1984.

[6] M. Uman, The lightning discharge, Academic Press, Florida, 1987.

[7] D.R. MacGorman and W.D. Rust, The electrical nature of storms, Oxford University Press, New York, 1998.

[8] J.A. Chalmers, Atmospheric Electricity, Pergamon, Oxford, London, 1967.

[9] O. Mendes Jr., O. Pinto Jr., I.R.C. Pinto, and M. Chryssafidis, "Basic Elements and Model Comparisons in Eletrodynamics: Lightning trajectory", In Proceedings, volume 2, pages 1149-1151, São Paulo, September 28- Oct 2 1997. International Congress of Geophysics, Brazilian Geophysical Society, 5., São Paulo, 1997, SBGF.

[10] O. Mendes Jr., O. Pinto Jr., I.R.C. Pinto, and M. Chryssafidis, "Lightning simulation: the stepped leader paths in the Earth's atmosphere.", In Proceedings, volume 1, pages 150-153, São Paulo, September 02-06
1996. VI Encontro Brasileiro de Física de Plasmas, Águas de Lindóia", SBF.

[11] W.A. Lyons, R.A. Armstrong, E.A. Bering III, and E.R. Williams, "The Hundred Year Hunt for the Sprite", EOS Transactions, 81,33, 373-375, August 15, 2000.

[12] O. Mendes Jr., M.O. Domingues, O. Pinto Jr., I.R.C. Pinto, and M.M. Saba, "Via-Lux Project: a quantitative imagery method for lightning event analysis", In Proceedings, volume 1, Rio de Janeiro, August 15-19 1999. International Congress of Geophysics, Brazilian Geophysical Society, 6., Rio de Janeiro, 1999, SBGF.

[13] C.A.A. Beneti, E.L. Alvim, S.A. Melo, L.A.R. Assunção, A.F. Cazetta, and R.J. Reis, RIDAT - Rede Integrada de Detecção de Descargas Elétricas Atmosféricas no Brasil: Situação Atual, Aplicações e Perspectivas. In Proceedings, Volume 1, Rio de Janeiro, Oct 16-20, 2000. Sociedade Brasileira de Meteorologia (CDROM), 